\title{
Recognition and Prevention of Bed Separation Water: Based on Trapezoid Platform Model
}

\author{
Ru Hu $\mathbb{D}$, Jiwen Wu $\mathbb{D}$, Xiaorong Zhai, and Wei Liu \\ School of Earth and Environment, Anhui University of Science and Technology, Huainan, 232001 Anhui, China \\ Correspondence should be addressed to Jiwen Wu; 564473701@qq.com
}

Received 23 December 2020; Revised 23 January 2021; Accepted 5 February 2021; Published 18 February 2021

Academic Editor: Feng Xiong

Copyright (C) $2021 \mathrm{Ru} \mathrm{Hu}$ et al. This is an open access article distributed under the Creative Commons Attribution License, which permits unrestricted use, distribution, and reproduction in any medium, provided the original work is properly cited.

\begin{abstract}
In recent years, bed separation water inrush, as a new type of water disaster, has posed serious threat to mining safety in China's many coal mines. This study focused on periodic water inrush accidents in the No. 7335 working face owned by Xuzhuang Coal Mine, Jiangsu Province, China. Based on the theory of key strata, the formation positions of the separation layer in the overlying strata were first identified; next, the trapezoid platform model of the fracture of the overlying strata was introduced for illustrating the evolutional process of the bed separation space and accurately calculating the position and the geometrical morphology of the bed separation space. On that basis, the relation between the fracture of the overlying stratum and the inrush of bed separation water was revealed with the use of the plate theory. Moreover, the prevention and control measures of the bed separation water were formulated. Research show that the arrangement of the diversion drilling holes can successfully eliminate the threat of the bed separation water to the lower working face.
\end{abstract}

\section{Introduction}

Coal field is formed by geologic sediments in history. The strata in most of coal mines are composed of sedimentary rocks mainly including sandstone, sandy mudstone, shale, limestone, and mudstone. During coal mining process, the overlying rocks undergo caving, fracture, bending, and sinking $[1-3]$ and gradually develop from bottom to top until the earth's surface; then, the ground subsidence occurs, accompanied with the formation of the caving zone, the fractured zone, and the bending subsidence zone, as shown in Figure 1. Because of the difference in lithology and thickness, the displacements of various overlying strata are not exactly same. In particular, for the overlying strata with interval distribution of soft and hard strata, the interlayer space can be formed under the displacement difference of the overlying strata in vertical direction, which is also referred to as the separation layer $[4,5]$. When the interlayer space satisfies a certain water storage condition, the bed separation water is formed, which is exactly like a huge water bag; after being fractured, the bed separation water rapidly floods into the lower stope face, which then triggers the water hazard in sep- aration layer $[6,7]$. Water disaster accidents frequently occur in some of China's coal mines with simple hydrogeological condition, during which the flooding of working faces and causalities can bring about great economic loss. The water accident caused by the bed separation water now has become a main hydrogeological hazard in coal mines.

19 typical separation-induced water disaster accidents occurred in China over the past 20 years, as the distribution shown in Figure 2. The most notorious accidents mainly include the water gushing accident induced by roof bed separation water in Laohutai Coal Mine, Liaoning of Northeast China, on March 10th, 2007, which caused 29 deaths. A water gushing accident induced by roof separation also occurred in Haizi Coal Mine, Anhui, China, on July 4th, 2007, and a similar accident also occurred in Zhaojin Coal Mine, Shaanxi of Northwest China, on April 25th, 2016, which caused 5 deaths and 11 deaths, respectively.

Scholars have laid extensive attention on the formation of the separation in recent years [8-12]. Gao divided the overlying strata after the mining into the fractured zone, the separation zone, the bending zone, and the loose alluvium zone [13]. Gui et al. and Jiang and Xu led their teams and focused 


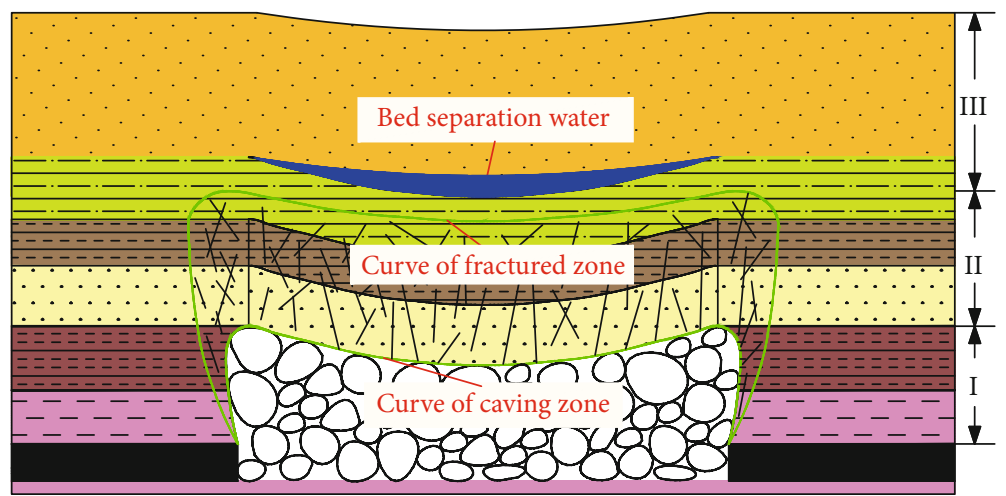

FIGURE 1: Illustration of separation development in a mine.

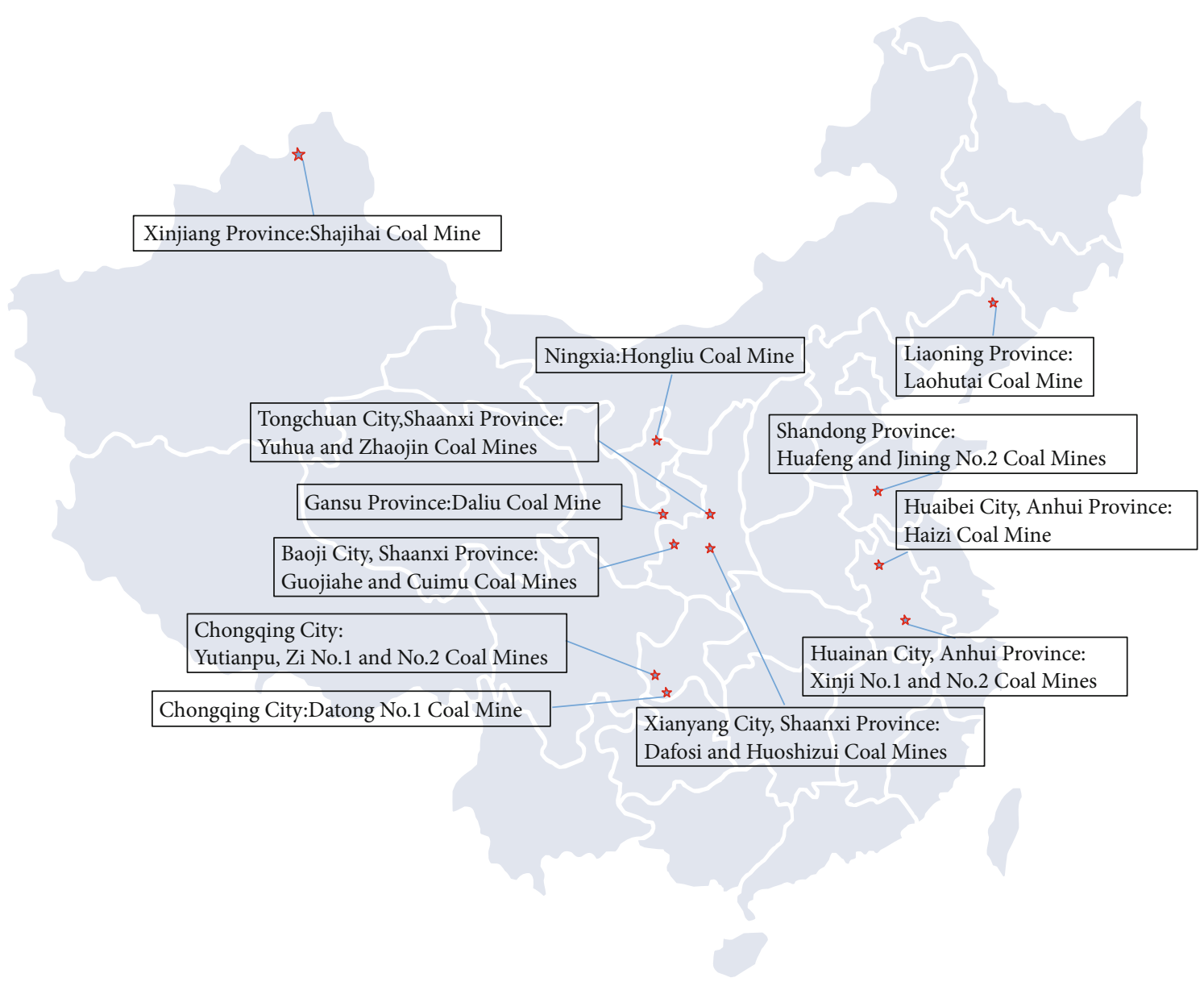

FIgURE 2: Distribution of bed separation water inrush accidents in China.

on the development rules of the separation layer; moreover, they quantitatively calculated the maximum development space of the separation layer [14-16]. Qian et al. and Xu et al. laid the research emphasis on the fracture and migration rules of the overlying strata after the mining and proposed the key stratum theory, which has provided important theoretical basis for investigating the formation mechanism of the separation layer [17-20]. Li et al. and $\mathrm{Li}$ and Qiao examined the formation reason of the separationinduced water disaster in the No. 745 working face owned by Haizi Coal Mine, Huaibei, China, and proposed some prevention measures [21, 22]. Based on the mechanical model of the deformation of the composition board, Yang et al. derived the practical formula for quantitatively calculating the separation position, which can provide important reference for grouting and the prevention of bed separation water disaster [23]. Teng and Yan conducted field monitoring on the migration of the overlying strata in the stope after the mining and revealed the dynamic development process of the separation [24]. Qiao et al. analyzed water inrush 
mechanism in the No. 21301 and No. 21302 working faces owned by Cuimu Coal Mine and qualitatively described the dynamic relations of the mining height and the advancing speed of the working face with the water accumulation volume in the separation space [25]. In addition, some scholars investigated the water in the separation layer from the perspectives of similarity model, monitoring, and prevention [26-34], which can effectively prevent the occurrence of separation-induced water disasters. These studies can provide clear idea and helpful reference for identifying and preventing the separation (water) below the overlying thick sandstone in the No. 7335 working face owned by Xuzhuang Coal Mine, Jiangsu. This study focused on the relative position relation between the separation space and the working face, revealed the reasons for periodic water inrushes, and formulated the detection and prevention measures of the separation (water) for adequately removing the safety threat of the bed separation water on the lower working face.

\section{Formation Condition and Identification of the Position of Bed Separation (Water)}

\subsection{Formation Condition of the Bed Separation Water}

(1) The existence of separation layer. As the mining face moves, a synchronized sedimentation of the overlying strata in the goaf may produce the separation layer especially between the thick/hard stratum and the soft/thin stratum. The existence of the separation layer is the prerequisite for the formation of bed separation water. Since being formed, the separation layer should exist for a certain period. If the separation layer exists for a short time from the production to closing, a small amount of water can supply the separation layer, and the separation layer can be rapidly destroyed, which imposes relatively low threat on the lower working face

(2) The existence of supplemental water around the separation layer. After the formation, the separation layer is only a space without water supply from the surrounding area and no bed separation water is produced. The existence of the surrounding water supply serves as the necessary condition for the formation of the bed separation water

(3) The location of the separation layer in the relative closed environment. After the formation of the separation layer, the separation space is always connected with the goaf. The surrounding water can be rapidly discharged to the goaf even if flowing into the separation layer, thereby failing in storing and forming the bed separation water. Only when the separation space is located in the enclosed environment and receives the supply from the surrounding water can water be accumulated in the separation layer and the bed separation water be formed

2.2. Identification of the Separation Position. Based on the research on the roof strata and practices for a number of years, Qian et al., the members of the Chinese Academy of Engineering, have proposed the key stratum theory in strata control [17]. After the mining of coal seam, the orderly deformation and the movements of the stratified structures with uneven thicknesses can be regarded as the bending deformation of many composition plates. The separation layer can be produced between the composite boards with different deflections. According to the elastic modulus, density, and thickness of the stratum, the number of the strata in each group of the composition board can be calculated. Assuming that each group of the composition board is composed of $n$ layers of strata, the load of the $n$th layer of the stratum on the first layer of the stratum at the bottom can be written as

$$
q_{n, 1}=\frac{E_{1} h_{1}^{3} \sum_{i=1}^{n} \gamma_{i} h_{i}}{\sum_{i=1}^{n} E_{i} h_{i}^{3}}=\frac{E_{1} h_{1}^{3}\left(\gamma_{1} h_{1}+\gamma_{2} h_{2}+\cdots+\gamma_{n} h_{n}\right)}{E_{1} h_{1}^{3}+E_{2} h_{2}^{3}+\cdots+E_{n} h_{n}^{3}}
$$

where $E_{1}, E_{2}, \cdots$, and $E_{n}$ are the elastic moduli of various layers of strata; $n$ denotes the number of the strata in this group; $h_{1}, h_{2}, \cdots$, and $h_{n}$ are the thicknesses of various layers of strata; $\gamma_{1}, \gamma_{2}, \ldots$, and $\gamma_{n}$ are the weights of various layers of strata.

When $q_{n, 1}>q_{n+1,1}$, the upper stratum imposes no load on the lower stratum, and the separation layer between two strata is produced. The discriminant for the formulation of the separation layer $\left(q_{n, 1}>q_{n+1,1}\right)$ can be expressed as

$$
\frac{E_{1} h_{1}^{3} \sum_{i=1}^{n} \gamma_{i} h_{i}}{\sum_{i=1}^{n} E_{i} h_{i}^{3}}>\frac{E_{1} h_{1}^{3} \sum_{i=1}^{n+1} \gamma_{i} h_{i}}{\sum_{i=1}^{n+1} E_{i} h_{i}^{3}}
$$

Through further organization, the following expression can be obtained:

$$
E_{n+1} h_{n+1}^{2} \sum_{i=1}^{n} \gamma_{i} h_{i}>\gamma_{n+1} \sum_{i=1}^{n} E_{i} h_{i}^{3}
$$

Only when the goaf has not been fully filled by the rocks in the caving zone after the excavation in the coal seam can the bed separation space be formed. The discriminant can thus be written as

$$
M-\sum\left(K_{i}-1\right) h_{i}>0
$$

where $M$ denotes the mining thickness of the coal seam; $h_{i}$ and $K_{i}$ are the original thickness and the bulking coefficient of the $i$ th layer stratum in the caving zone after coal mining. Only when Equations (3) and (4) can be satisfied the overlying strata in the coal seam have the sufficient space for the development of the bed separation, and the maximum separation amount in the overlying strata is also restricted by the value on the left side of Equation (4). The developed bed separation space is larger for the coal seam with greater mining thickness. 


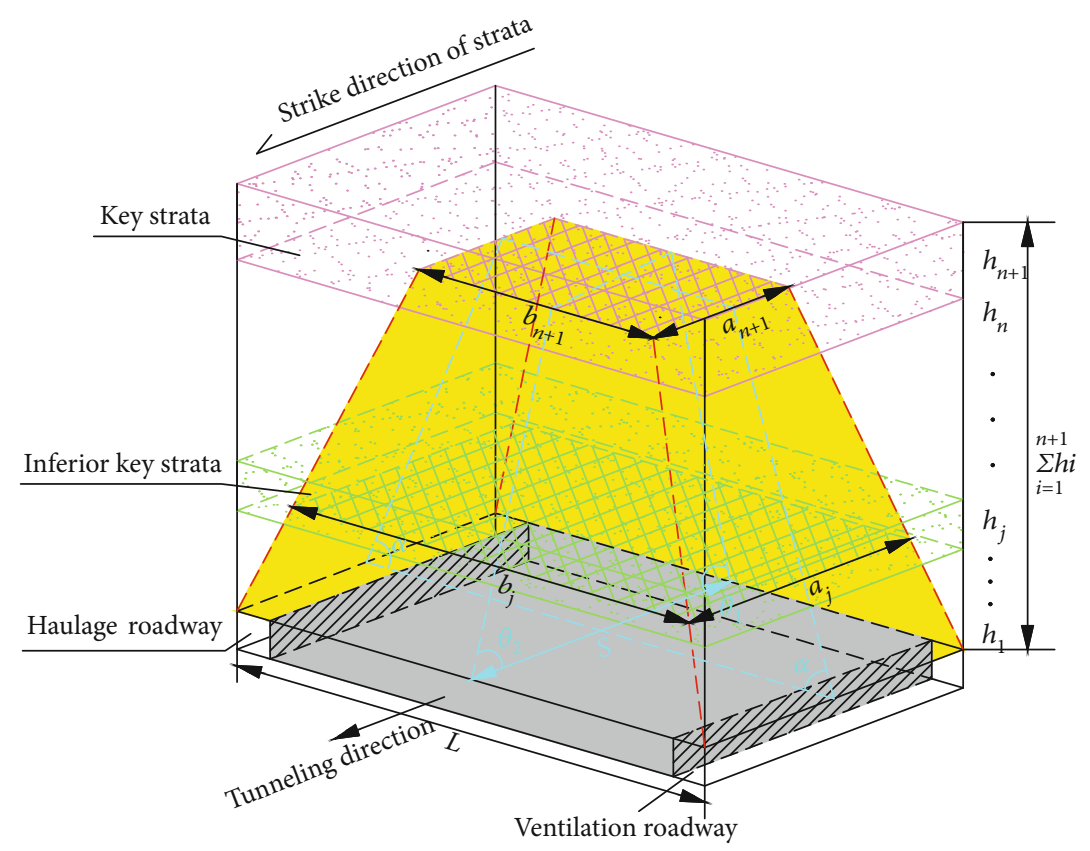

FIGURE 3: Graphic model of the fracture mode of the overlying strata in the working face.

\section{Relative Position between the Separation Space and the Working Face}

Generally, more than one separation layer develops in the overlying strata after the mining of coal seam, and the developed separation layers are not fixed. During coal mining process, the goaf increases in volume, and the development height of the separation layer in vertical direction increases constantly; meanwhile, the upper separation layers develop gradually while the lower separation layers are gradually closed. Each separation layer undergoes a dynamic process from starting, development, stability, and closing. Accompanied with the development, stability, and closing of the separation space, the separation space moves forward with the working face, and the maximum separation space appears in periodic pattern [35].

Therefore, the key in separation layer (water) research is to determine the position of the separation space including the geometrical size of the separation layer (length and height), the distance between the separation layer and the cutting hole, and the relation between the separation layer and the advancing length of the working.

Based on a lot of numerical simulation and physical simulation results, the overlying strata underwent trapezoidtable fracture pattern (see Figure 3) [36-38]. In this study, the trapezoid platform model of the fracture of the overlying strata was firstly applied to the location of the separation layer. As shown in Figure 3, assuming two key strata (the $j$ th and the $(n+1)$ th layers) exist and the separation layer is located between the $j$ th and the $(n+1)$ th layers, the relation between the geometrical morphology of the separation layer and the advancing distance of the working face is then explained in detail by taking the condition of the $j$ th layer as the example.
When the working face moves forward by a distance of $S$, since the breaking angles of the strata are different $\left(\theta_{1}, \theta_{2}\right)$ in strike direction [39], the relation between the hanging length of the key stratum in the strike direction $\left(a_{j}\right)$ and $S$ when the separation space first appeared below the $j$ th layer (the key stratum) can be written as

$$
a_{j}=s-\cot \theta_{1} \sum_{i=1}^{j-1} h_{i}-\cot \theta_{2} \sum_{i=1}^{j-1} h_{i},
$$

where $\theta_{1}$ denotes the breaking angle of the stratum at the cutting hole, with a unit of degree; $\theta_{2}$ denotes the breaking angle of the stratum in the front of the working face, with a unit of degree; $a_{j}$ denotes the hanging length of the key stratum in strike direction, with a unit of meter; and $S$ denotes the advancing distance of the working face, with a unit of meter.

The hanging width of the key stratum in the inclination direction $\left(b_{j}\right.$, with a unit of $\left.\mathrm{m}\right)$ and the width of the working face ( $L$, with a unit of $\mathrm{m}$ ) obey the following relation:

$$
b_{j}=L-2 \cot \alpha \sum_{i=1}^{j-1} h_{i}
$$

where $b_{j}$ denotes the hanging width of the key stratum in inclination direction, with a unit of meter, and $L$ denotes the width of the working face, with a unit of meter.

When the bed separation space first appears below the $j$ th stratum, the maximum separation space exhibits periodic change along the advancing direction; however, the vertical distance between the separation space and the working face remains unchanged. The separation layer constantly develops upward in the vertical direction until the bottom of 
the key stratum. Therefore, the position of the separation space on the bottom of the main key stratum can be derived in the same manner.

\section{Application and Discussion}

This study focused on Xuzhuang Coal Mine in Jiangsu Province of northern China for in-detail analysis. Thick sandstone strata (also referred to as thick-bedded sandstone) develop at the boundary between the Shihezi formation and the Shanxi formation under Xuzhuang Coal Mine, with a two-stage thickness and a mean thickness of $16.74 \mathrm{~m} 21.54 \mathrm{~m}$ and $17.03 \mathrm{~m}$, respectively. The geological prospecting data reveal well development of the fractures in the sandstone stratum. The specific capacity was $0.023 \mathrm{~L} /(\mathrm{s} \cdot \mathrm{m})$, suggesting favorable water abundance. The sandstone stratum was $53 \mathrm{~m} \sim 70 \mathrm{~m}$ away from the underground No. $7^{\#}$ coal seam. Only when the separation layer was formed between the thick-bedded sandstone stratum and the coal seam can the convergence of bed separation water pose serious threat to the safety in the stope. Therefore, the trapezoid platform mode of the overlying failure was applied to the No. 7335 fully mechanized mining face in Xuzhuang Coal Mine for investigating the judgment and prevention of the separation layer.

4.1. Overview of the Working Face. The No. $7^{\#}$ coal seam of Shanxi formation is the primary mineable coal seam in the No. 7335 fully mechanized working face with a strike length of $881.2 \mathrm{~m}$ and an inclination length of $172 \mathrm{~m}$. The mean thickness and the mean inclination angle were $5.75 \mathrm{~m}$ and $13.5^{\circ}$, respectively. The mining elevation ranged from $-583 \mathrm{~m}$ to $-521 \mathrm{~m}$. The strata $107.33 \mathrm{~m}$ above the No. $7^{\#}$ coal seam were the Permian strata mainly composed of the mudstone, the sandy mudstone, the siltstone, the fine sandstone, the medium sandstone, and the coarse sandstone (with the serial number of $1 \sim 14$, as shown in Table 1 ). The upper roof of the No. $7^{\#}$ coal seam was composed of fine sandstone with a mean thickness of $11.54 \mathrm{~m}$. Averagely, the thick-bedded sandstone with a mean thickness of $19.12 \mathrm{~m}$ was $57.15 \mathrm{~m}$ away from the No. $7^{\#}$ coal seam.

In the early stage of the mining, four great instantaneous water burst accidents struck the No. 7335 working face. The working face moved $227 \mathrm{~m}$ in total. A great amount of water inflow may stop work and production, which thereby created trouble for the advancing of the working face. Figure 4 shows the relation between the maximum water inflow and the advancing distance of the working face during the early stage of the mining.

As shown in Figure 4, the maximum water inflow appears alternately in a small cycle pattern and a great cycle pattern. The advancing distance corresponding to the small cycle ranged from $23.4 \mathrm{~m}$ to $32.4 \mathrm{~m}$, with a mean value of $27.7 \mathrm{~m}$, while the advancing distance corresponding to the great cycle was $52.2 \mathrm{~m} \sim 66.6 \mathrm{~m}$, with a mean value of $56.75 \mathrm{~m}$. The KJ216 ground pressure monitoring system was installed in the No. 7335 working face. Based on the monitoring data, the maximum and the minimum peaks of the maximum water inflow appeared synchronously with the roof weighting, which confirmed that roof movement caused the change of water volume. It can also be observed that the water inflow volume was great in the early stage of four water inrush accidents but decayed rapidly. The water inrush characteristics fit with the characteristics of water inrush in the old goaf and also similar to water inrush features in separation-induced water disaster.

4.2. Identification and Exploration of the Separation Space. The position of the stratum where the separation space appears can be judged by Equation (3). When the left side of Equation (3) exceeds the right side, the separation space is formed; otherwise, no separation space is formed. Table 1 shows the judgement results. The positions where the separation space was formed satisfy the condition in Equation (4).

As shown in Table 1, the separation space can be observed in the $1 \mathrm{st} / 2 \mathrm{nd}, 5 \mathrm{th} / 6 \mathrm{th}$, and $13 \mathrm{rd} / 14$ th strata. To be specific, the separation space between the 1st and the 2nd strata can rapidly disappear with the rock caving, thereby imposing no threat to the mining in the working face. The separation space between the 5th and the 6th strata developed on the fractured zone, and a sandy mudstone layer with favorable water insulation capability was located below the separation space; the separation space can receive the supply from the thick-bedded sandstone aquifer and posed great water disaster threat to the lower working face. The separation space between the 13rd and the 14th strata received no supply from the water source and posed no threat on the safety in the working face since it was far away from the lower working face. In order to further explore whether the separation space and the separation space existed below the thick-bedded sandstone, the hole was drilled from the construction ground to below the thick-bedded sandstone, which was $257 \mathrm{~m}$ away from the cutting hole in the working face, as shown in Figure 5.

Next, the development of the separation layer was observed by using a color borehole TV observation method [40]. As the working face moved to $270 \mathrm{~m}$ away, the separation layer appeared below the thick-bedded sandstone. As the working face further advanced, the separation space developed gradually, and a great amount of water flowed out from the drilling hole. As the working face moved to $283 \mathrm{~m}$ away, the separation space shrunk suddenly and disappeared soon, which can verify the idea of the bed separation water.

4.3. Relation between the Fracture of the Overlying Strata and Periodic Water Inrush in the Working Face. According to the fracture plate theory of the roof key stratum [17], the first stratum fracture and the periodic fracture under any mining boundary conditions should satisfy the following expression:

$$
a=L_{\mathrm{m}} \cdot \omega
$$

where $\alpha$ denotes the breaking distance of the stratum at different boundary conditions, with a unit of meter; $L_{\mathrm{m}}$ denotes the span criterion, with a unit of meter; and $\omega$ denotes the geometrical coefficient. 
TABLE 1: Judgment results of the development position of the separation space.

\begin{tabular}{|c|c|c|c|c|c|c|c|}
\hline \multirow[t]{2}{*}{ Stratum } & \multirow[t]{2}{*}{ Lithology } & \multirow[t]{2}{*}{$\gamma\left(\mathrm{KN} \cdot \mathrm{m}^{-3}\right)$} & \multirow[t]{2}{*}{$E(\mathrm{GPa})$} & \multirow[t]{2}{*}{$h(\mathrm{~m})$} & \multirow[t]{2}{*}{$\sigma_{\mathrm{s}}(\mathrm{MPa})$} & \multicolumn{2}{|c|}{$\begin{array}{c}\text { Are there separated strata } \\
\text { below this layer? }\end{array}$} \\
\hline & & & & & & Equation (2) left & Equation (2) right \\
\hline \multirow[t]{2}{*}{19} & Sandy mudstone & 24.5 & 5.49 & 14.15 & 0.46 & & \\
\hline & & & & & & & $\mathrm{N}$ \\
\hline \multirow[t]{2}{*}{18} & Siltstone & 25.4 & 3.32 & 1.52 & 0.83 & 732430.0429 & 936377.5484 \\
\hline & & & & & & & $\mathrm{N}$ \\
\hline \multirow[t]{2}{*}{17} & Fine sandstone & 26.2 & 16.55 & 2.27 & 2.83 & 4732.424296 & 970478.9473 \\
\hline & & & & & & & N \\
\hline \multirow[t]{2}{*}{16} & Sandy mudstone & 23.50 & 5.23 & 3.03 & 0.48 & 47542.8526 & 995973.2413 \\
\hline & & & & & & & N \\
\hline \multirow[t]{2}{*}{15} & Siltstone & 25.40 & 3.32 & 3.47 & 0.83 & 24756.77187 & 927546.0072 \\
\hline & & & & & & & N \\
\hline \multirow[t]{2}{*}{14} & Medium-grained sandstone & 26.50 & 11.38 & 14.91 & 1.49 & 15795.03335 & 958095.7396 \\
\hline & & & & & & & Y \\
\hline \multirow[t]{2}{*}{13} & Gritstone & 28.40 & 7.87 & 2.58 & 0.98 & 2310660.863 & 2123305.968 \\
\hline & & & & & & & N \\
\hline \multirow[t]{2}{*}{12} & Mudstone & 23.80 & 1.54 & 2.51 & 0.32 & 44008.37238 & 2271704.583 \\
\hline & & & & & & & N \\
\hline \multirow[t]{2}{*}{11} & Sandy mudstone & 25.50 & 5.58 & 3.34 & 0.53 & 7571.007959 & 19009172.85 \\
\hline & & & & & & & N \\
\hline \multirow[t]{2}{*}{10} & Siltstone & 25.40 & 3.32 & 1.16 & 0.83 & 43481.21046 & 1954054.743 \\
\hline & & & & & & & N \\
\hline \multirow[t]{2}{*}{9} & Sandy mudstone & 22.70 & 5.79 & 2.57 & 0.48 & 2988.90415 & 2025704.718 \\
\hline & & & & & & & N \\
\hline \multirow[t]{2}{*}{8} & Fine sandstone & 26.20 & 16.55 & 0.97 & 2.83 & 22337.4331 & 1951607.183 \\
\hline & & & & & & & N \\
\hline \multirow[t]{2}{*}{7} & Sandy mudstone & 24.50 & 3.58 & 3.02 & 0.49 & 9042.13227 & 2134414.478 \\
\hline & & & & & & & N \\
\hline \multirow[t]{2}{*}{6} & Medium-grained sandstone & 26.50 & 11.38 & 19.12 & 1.49 & 16543.62489 & 1948821.267 \\
\hline & & & & & & & Y \\
\hline \multirow[t]{2}{*}{5} & Sandy mudstone & 23.95 & 5.45 & 11.53 & 0.41 & 4724814.07 & 1896664.291 \\
\hline & & & & & & & N \\
\hline \multirow[t]{2}{*}{4} & Medium-grained sandstone & 26.50 & 11.38 & 3.12 & 1.23 & 610243.8963 & 1551480.317 \\
\hline & & & & & & & $\mathrm{N}$ \\
\hline \multirow[t]{2}{*}{3} & Sandy mudstone & 25.12 & 5.18 & 19.11 & 1.48 & 85358.80561 & 1668972.69 \\
\hline & & & & & & & N \\
\hline \multirow[t]{2}{*}{2} & Fine sandstone & 26.20 & 16.55 & 11.54 & 2.83 & 594033.2438 & 623134.0871 \\
\hline & & & & & & & Y \\
\hline 1 & Sandy mudstone & 24.50 & 5.38 & 11.85 & 0.45 & 639873.3909 & 234551.7178 \\
\hline 0 & $7^{\#}$ coal seam & 21.31 & 1.31 & 5.75 & 0.28 & & \\
\hline
\end{tabular}

By ignoring the effects of the boundary condition and the hanging width, $L_{\mathrm{m}}$ can be understood as the limit span when the clamped widths on four sides were infinitely great and thus is written as

$$
L_{\mathrm{m}}=\frac{h}{1-\mu} \sqrt{\frac{2 \sigma_{s}}{q}},
$$

where $h$ denotes the thickness of the stratum, with a unit of meter; $\mu$ denotes the Poisson ratio of the stratum; $q$ denotes the stratum's self weight and the overlying load, with a unit of megapascal; and $\sigma_{s}$ denotes the stratum's tensile strength, with a unit of megapascal.

The No. 7335 working face was adjacent to the goaf. The boundary condition of the overlying strata can be described as the plate clamped on three sides and simply supported on one side. The corresponding boundary and 


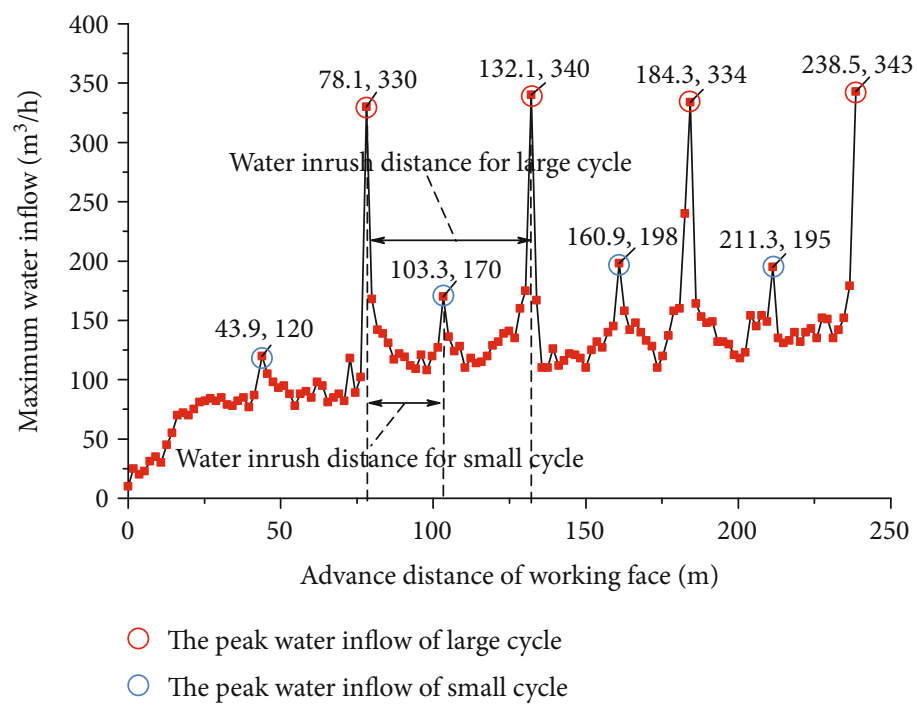

FIGURE 4: Relation between the advancing distance of the working face and the corresponding water inflow.

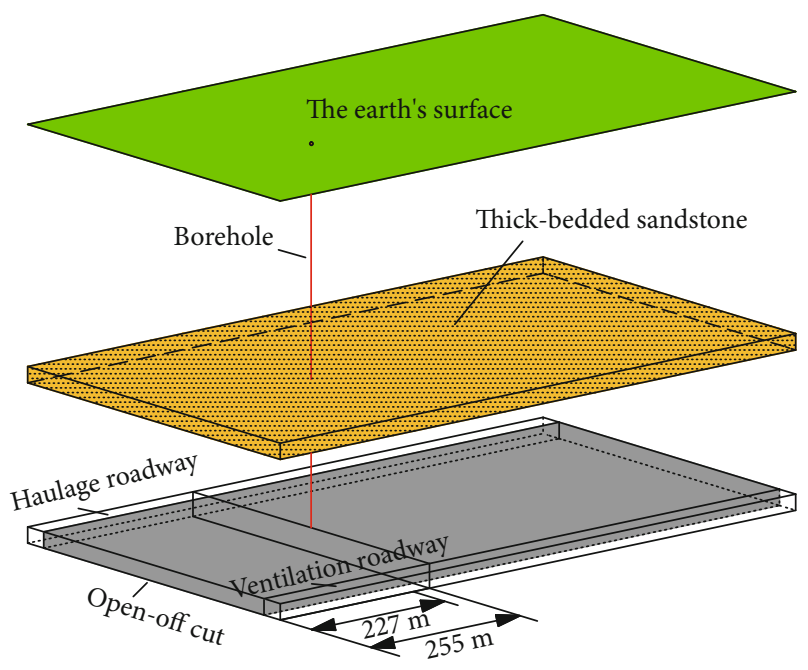

FIGURE 5: Illustration of the drilling position on the ground.

width influencing coefficients at the first fracture can be written as

$$
\left\{\begin{array}{l}
\omega=\sqrt{2 \times \frac{2+\lambda^{4}}{4+3 \mu \lambda^{2}}} \\
\lambda=\frac{a_{\mathrm{f}}}{b}
\end{array}\right.
$$

When the inferior key stratum was periodically fractured, the boundary condition can be described as the plate simply supported on two sides, and the corresponding boundary and width influencing coefficients can be written as

$$
\left\{\begin{array}{l}
\omega=\sqrt{\frac{2}{3} \times \frac{1+\lambda^{4}}{1+3 \mu \lambda^{2}}}, \\
\lambda=\frac{a_{\mathrm{p}}}{b},
\end{array}\right.
$$

where $\lambda$ denotes the length-to-width ratio of the outcrop; $a_{\mathrm{f}}$ denotes the first fracture step of the hanging stratum, with a unit of meter; $a_{\mathrm{p}}$ denotes the periodic fracture step of the handing stratum, with a unit of meter; and $b$ denotes the handing width of the stratum, with a unit of meter.

According to Equation (6), the handing lengths of the 2nd and the 6th strata were $b_{2}=162.90 \mathrm{~m}$ and $b_{6}=128.12 \mathrm{~m}$, respectively. By combining Equations (1), (8), (9), and (10), it can be calculated that the first caving step and the periodic caving step of the 2 nd stratum were $a_{2 \mathrm{f}}=34.02 \mathrm{~m}$ and $a_{2 \mathrm{p}}=$ $27.77 \mathrm{~m}$, while the first caving step and the periodic caving step of the 6 th stratum were $a_{6 \mathrm{f}}=68.34 \mathrm{~m}$ and $a_{6 \mathrm{p}}=55.67$ $\mathrm{m}$, respectively. Based on field observation results, $\theta_{1}=69^{\circ}$, $\theta_{2}=63^{\circ}$, and $\alpha=69^{\circ}$. The Poisson ratios of the fine sandstone and the medium sandstone were 0.28 and 0.33 , respectively.

As shown in Figure 3, in the early stage of mining, when the working face moved to $43.9 \mathrm{~m}$ and $78.1 \mathrm{~m}$ away, great water inrush appeared in the working face. According to Equation (5), as the working moved to $43.9 \mathrm{~m}$ away, the hanging length of the 2 nd stratum in strike direction was $a_{2}$ $=33.31 \mathrm{~m}$; as the working moved to $78.1 \mathrm{~m}$ away, the hanging length of the 6 th stratum in strike direction was $a_{6}=$ $67.51 \mathrm{~m}$. The first caving steps of the $2 \mathrm{nd}$ and the 6th strata were $34.02 \mathrm{~m}$ and $68.34 \mathrm{~m}$, respectively, which indicates direction correlation between water inrush in the working face and the fracture of the overlying strata. When the 2 nd and the 6th strata were fractured for the second time, the water in the roof sandstone served as the direct water source and rushed into the working face. The fracture of the 6th stratum led to synchronous fracture of the lower stratum, thereby inducing large-area roof weighting in the working face; accordingly, the bed separation water rapidly rushed into the working face along the fractures. In the subsequent excavating process, the 2 nd and the 6th strata underwent periodic fractures with large/small alternate periods, and the water inflow in the working face also changed alternately in large and small periods accompanied with the periodic stratum fracture. 


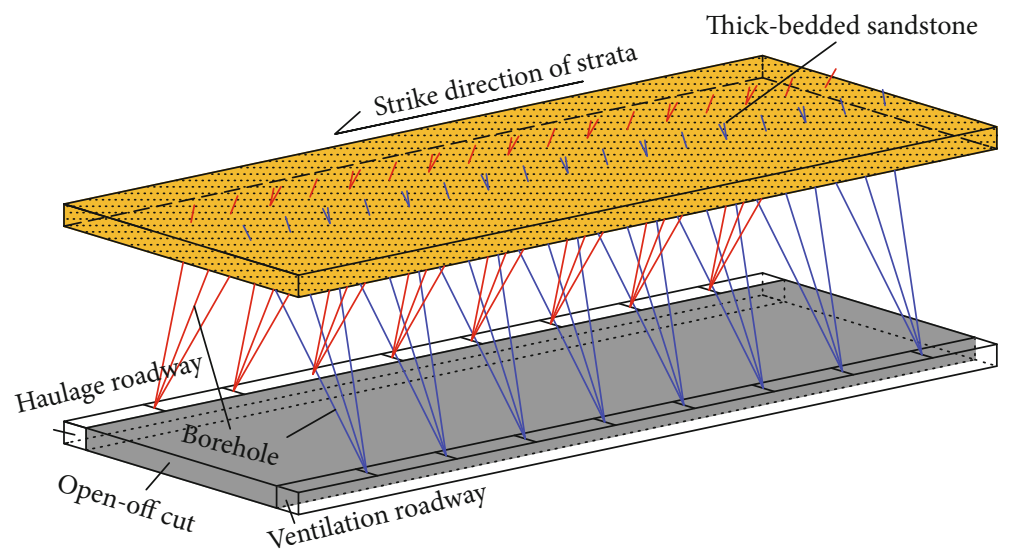

Figure 6: Layout of the diversion drilling holes.

Based on above analysis, the introduction of the trapezoid platform model of the fracture of the overlying strata and the plate theory of the stratum fracture can accurately predict the spatial development position of the bed separation water and water inrush rules, thereby providing reliable basis for the treatment of the bed separation water.

4.4. Prevention and Control of the Bed Separation Water. By destroying the integrity of the separation space, the originally enclosed separation layer can be connected with the lower stope so as to prevent water accumulation in the bed separation water and form the bed separation water; i.e., the prevention and control goal can be achieved. The diversion drilling holes were arranged along the machine roadway and the airflow roadway, as shown in Figure 6. The drilling nests were arranged at an interval of $50 \mathrm{~m}$, and three holes were located within each drilling nest in a fan-shaped distribution pattern. Therefore, the drilling holes show meshed distribution and passed through the thick-bedded sandstone above the separation space. The end hole passed through the top of the thick-bedded sandstone by $10 \mathrm{~m}$, and the steel screens with a diameter of $91 \mathrm{~mm}$ acted as the filter (see Figure 7) so as to prevent the blockage of the hole induced by the falling of gangues and ensure sustainably effective drainage in the drilling hole.

After the mining in the working face finished, $1,100,000 \mathrm{~m}^{3}$ water was discharged from the bed separation space in the drilling holes. No increase of periodic water gush in the early stage of the mining appeared in the working face; i.e., the threat of the instantaneous gushing of the bed separation water on the working face can be eliminated. Accordingly, it can be concluded that the arrangement of the drainage holes in the working face was effective and successful.

\section{Conclusions}

The results obtained made it possible to draw the following conclusions.

(1) Using the key strata theory, the position of the separation layer in the overlying strata of the no. 7335

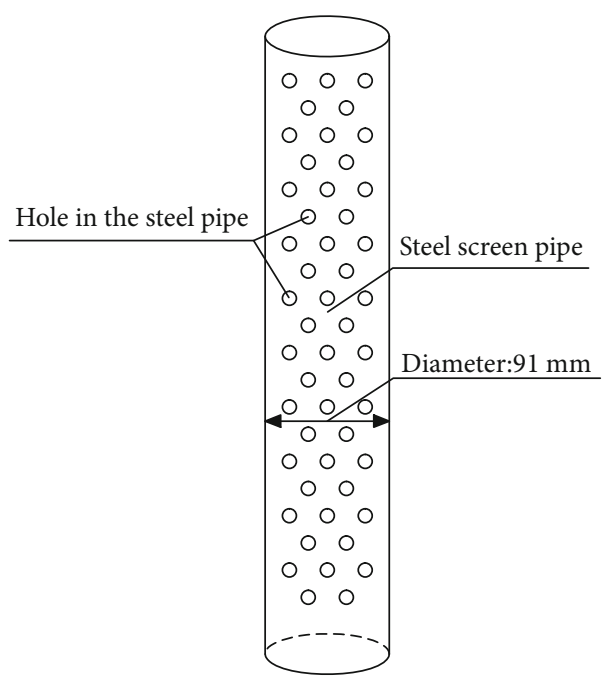

FIgURE 7: Illustration of the steel screen pipe.

working face owned by Xuzhuang Coal Mine, Jiangsu, China, was identified. Moreover, the identification results were verified by color borehole television images

(2) The trapezoid platform model for describing the fracture of the overlying stratum was introduced for revealing the evolutional process of the separation space in vertical and horizontal directions. Further, the position and mode of the separation space were accurately calculated

(3) Based on the trapezoid platform model, the first fracture step of the thick-bedded sandstone was calculated as $68.344 \mathrm{~m}$ with the use of the plate theory; additionally, the periodic fracture step was $55.67 \mathrm{~m}$ and the inrush period of the bed separation water was $56.75 \mathrm{~m}$ in average

(4) By combining the calculation results of the periodic fracture step in the key strata and field ground pressure monitoring results, it can be concluded that the 
fracture of the key stratum is the immediate cause for periodic inrush of the bed separation water. The calculation data fit well with the field monitoring data. The prevention and control measures of the bed separation water were formulated, which successfully eliminated the threat of the bed separation water on the working face

\section{Data Availability}

The data used for calculation in this paper can be obtained from the author.

\section{Conflicts of Interest}

The authors declare that they have no conflicts of interest.

\section{Acknowledgments}

The authors are grateful for the financial support provided by Innovation team construction project of university scientific research platform in Anhui Province (2016-2018-24) and the National Natural Science Foundation of China (Grant no. 41272278).

\section{References}

[1] BMRI (Beijing Mining Research Institute of China Coal Research Institute), Patterns of Surface Movement and Overlying Strata Deformation in Coal Mines and Applications, China Coal Industry Publishers, Beijing, 1981.

[2] Z. Q. Wang, P. F. Li, L. Wang, Y. Gao, X. F. Guo, and C. F. Chen, "Method of division and engineering use of "three band" in the stope again," Journal of China Coal Society, vol. 38, no. s2, pp. 287-293, 2013.

[3] Y. F. Gao, Z. Y. Deng, Z. D. Yang, W. C. Li, and H. R. Xie, "Theoretical study of subsidence reduction by grouting in overlying rock separation zone," Journal of Mining and Safety Engineering, vol. 4, no. 5, pp. 65-67, 2001.

[4] J. L. Xu, M. G. Qian, and H. W. Jin, "Study and application of bed separation distribution and development in the process of strata movement," Journal of Mining and Safety Engineering, vol. 26, no. 5, pp. 622-636, 2004.

[5] J. Q. Jiang, P. Wang, Q. L. Wu, and P. P. Zhang, "Evolution laws and prediction of separated stratum space under overlying high-position magmatic rocks," Chinese Journal of Geotechnical Engineering, vol. 37, no. 10, pp. 1769-1779, 2015.

[6] X. Zhang, W. Qiao, L. J. Lei, and F. S. Zeng, "Formation mechanism of overburden bed separation in fully mechanized topcoal caving," Journal of China Coal Society, vol. 41, no. s1, pp. 342-349, 2016.

[7] M. L. Xu, X. G. Zhu, and D. S. Zhao, "Study on surface subsidence and separation range thick seam mining of Daping mine," Advanced Materials Research, vol. 742, pp. 268-271, 2013.

[8] G. L. Liu, K. G. Fan, and T. Q. Xiao, "Study on mountainous shallow-buried coal seam mining working face strata behaviors and overlying strata movement features," Applied Mechanics and Materials, vol. 121-126, pp. 2911-2916, 2011.

[9] V. Palchik, "Localization of mining-induced horizontal fractures along rock layer interfaces in overburden: field measure- ments and prediction,” Environmental Geology, vol. 48, no. 1, pp. 68-80, 2005.

[10] D. Xuan and J. Xu, "Grout injection into bed separation to control surface subsidence during longwall mining under villages: case study of Liudian coal mine, China," Natural Hazards, vol. 73, no. 2, pp. 883-906, 2014.

[11] Q. X. Meng, H. Wang, M. Cai, W. Y. Xu, X. Y. Zhuang, and T. Rabczuk, "Three-dimensional mesoscale computational modeling of soil-rock mixtures with concave particles," Engineering Geology, vol. 277, p. 105802, 2020.

[12] J.-H. He, W.-p. Li, Y. Liu, Z. Yang, S.-L. Liu, and L.-F. Li, “An improved method for determining the position of overlying separated strata in mining," Engineering Failure Analysis, vol. 83, pp. 17-29, 2018.

[13] Y. F. Gao, "Four-zone model of rock mass movement and back analysis of dynamic displacement," Journal of China Coal Society, vol. 21, no. 1, pp. 51-55, 1996.

[14] Y. Jiang and Y. M. Xu, "Calculation of overburden strata separation in mining," Journal of Mining And Strata Control Engineering, vol. 26, no. 3, pp. 41-42, 1997.

[15] H. Gui, M. Lin, and X. Song, "Identification and application of roof bed separation (water) in coal mines," Mine Water and the Environment, vol. 37, no. 2, pp. 376-384, 2018.

[16] Y. Wang, B. Zhang, S. H. Gao, and C. H. Li, "Investigation on the effect of freeze-thaw on fracture mode classification in marble subjected to multi-level cyclic loads," Theoretical and Applied Fracture Mechanics, vol. 111, p. 102847, 2021.

[17] M. G. Qian, J. L. Xu, and X. X. Miao, "Theoretical study of key stratum in ground control," Journal of China Coal Society, vol. 21, no. 3, pp. 225-230, 1996.

[18] J. L. Xu, X. Z. Wang, W. T. Liu, and Z. G. Wang, "Effects of primary key stratum location on height of water flowing fracture zone," Chinese Journal of Rock Mechanics and Engineering, vol. 28, no. 2, pp. 380-385, 2009.

[19] J. L. Xu, M. G. Qian, and H. W. Jin, "Study and application of bed separation distribution and development in the process of strata movement," Chinese Journal of Rock Mechanics and Engineering, vol. 24, no. 5, pp. 632-636, 2004.

[20] Z. G. Tao, C. Zhu, M. C. He, and M. Karakus, "A physical modeling-based study on the control mechanisms of negative Poisson's ratio anchor cable on the stratified toppling deformation of anti- inclined slopes," International Journal of Rock Mechanics and Mining Sciences, vol. 138, p. 104632, 2021.

[21] W. P. Li, X. Q. Li, and R. H. Sun, "Preliminary study on dynamic water inrush of coal mining under super-thick dead rock," Journal of Engineering Ceology, vol. 16, no. s1, pp. 380-385, 2008.

[22] W. P. Li and W. Qiao, "Formation mechanism of dynamic impact failure zone of super dynamic water inrush in coal mine," Chinese Journal of Geotechnical Engineering, vol. 33, no. 11, pp. 1726-1733, 2011.

[23] L. Yang, G. M. Yu, X. C. Wang, R. Tian, and L. H. Li, "Calculation of position of separated strata due to mining in coal mine," Journal of China Coal Society, vol. 22, no. 5, pp. 477480, 1997.

[24] Y. H. Teng and Z. B. Yan, "Study on law of overburden split developing in mining process," Journal of China Coal Society, vol. 24, no. 1, pp. 25-28, 1999.

[25] W. Qiao, Y. Huang, and Z. B. Yuan, "Formation and prevention of water inrush from roof bed separation with fullmechanized caving mining of ultra-thick coal seam," Chinese 
Journal of Rock Mechanics and Engineering, vol. 33, no. 10, pp. 2076-2084, 2014.

[26] M. S. Diederichs and P. K. Kaiser, "Stability of large excavations in laminated hard rock masses: the voussoir analogue revisited," International Journal of Rock Mechanics and Mining Sciences, vol. 36, no. 1, pp. 97-117, 1999.

[27] W. Gong, Y. Peng, H. Wang, M. He, L. R. E. Sousa, and J. Wang, "Fracture angle analysis of rock burst faulting planes based on true-triaxial experiment," Rock Mechanics and Rock Engineering, vol. 48, no. 3, pp. 1017-1039, 2015.

[28] D. S. Zhao, X. L. Fan, W. S. Liu, and Q. H. Sun, "Analysis of the effect of geologic and mining factors on the law of separated strata distribution," Journal of Liaoning Technical University, vol. 17, no. 2, pp. 119-123, 1998.

[29] E. Can, Ç. Mekik, Ş. Kuşcu, and H. Akçın, "Monitoring deformations on engineering structures in Kozlu hard coal basin," Natural Hazards, vol. 65, no. 3, pp. 2311-2330, 2013.

[30] J. Chai, J.-x. Liu, B. Qiu et al., "Detecting deformations in uncompacted strata by fiber Bragg grating sensors incorporated into GFRP," Tunnelling and Underground Space Technology, vol. 26, no. 1, pp. 92-99, 2011.

[31] Z. Li, S. Liu, W. Ren, J. Fang, Q. Zhu, and Z. Dun, "Multiscale laboratory study and numerical analysis of water-weakening effect on shale," Advances in Materials Science and Engineering, vol. 2020, Article ID 5263431, 14 pages, 2020.

[32] D. Zhang, J. Wang, P. Zhang, and B. Shi, "Internal strain monitoring for coal mining similarity model based on distributed fiber optical sensing," Measurement, vol. 97, pp. 234-241, 2017.

[33] S. G. Chen and W. Hu, "A comprehensive study on subsidence control using COSFLOW," Geotechnical and Geological Engineering, vol. 27, no. 3, pp. 305-314, 2009.

[34] W. Guo, Y. Li, D. Yin, S. Zhang, and X. Sun, "Mechanisms of rock burst in hard and thick upper strata and rock-burst controlling technology," Arabian Journal of Geosciences, vol. 9, no. $10,2016$.

[35] W. Qiao, W. P. Li, and X. Q. Li, "Mechanism of"hydrostatic water-inrush" and countermeasures for water inrush in roof bed separation of a mining face," Journal of Mininger Safety Engineering, vol. 28, no. 1, pp. 96-103, 2011.

[36] Y. J. Sun and J. P. Zuo, "Micro-seismic monitoring on fractured zone and water inrush mechanism analysis of deep mining above aquifer in Xingdong coalmine," Rock and Soil Mechanics, vol. 38, no. 8, pp. 2335-2342, 2017.

[37] J. Ju and J. Xu, "Structural characteristics of key strata and strata behaviour of a fully mechanized longwall face with 7.0 $\mathrm{m}$ height chocks," International Journal of Rock Mechanics and Mining Sciences, vol. 58, no. 1, pp. 46-54, 2013.

[38] C. Liu, Z. H. Liu, and J. W. Zhang, "Effect of mining face length on the evolution of spatial structure of overlying strata and the law of underground pressure in large mining height face," Rock and Soil Mechanics, vol. 39, no. 2, pp. 691-698, 2018.

[39] B. Xu, J. Q. Jiang, and J. Dai, "Mechanical derivation and experimental simulation of breaking angle of key strata in overlying strata," Journal of China Coal Society, vol. 43, no. 3, pp. 599-606, 2018.

[40] D. M. Yang, W. B. Guo, and G. B. Zhao, "Height of waterconducting zone in longwall top-coal caving mining under thick alluvium and soft overburden," Journal of China Coal Society, vol. 44, no. 11, pp. 3308-3316, 2019. 